\title{
Eating at fast-food restaurants is associated with dietary intake, demographic, psychosocial and behavioural factors among African Americans in North Carolina
}

\author{
Jessie A Satia ${ }^{1,2, *}$, Joseph A Galanko ${ }^{3}$ and Anna Maria Siega-Riz ${ }^{1}$ \\ 'Department of Nutrition, University of North Carolina at Chapel Hill, Chapel Hill, NC, USA: ${ }^{2}$ Lineberger \\ Comprehensive Cancer Center, University of North Carolina at Chapel Hill, Chapel Hill, NC, USA: ${ }^{3}$ Division of \\ Gastroenterology and Hepatology, University of North Carolina at Chapel Hill, Chapel Hill, NC, USA
}

Submitted 20 April 2004: Accepted 25 July 2004

\begin{abstract}
Objective: To examine associations of the frequency of eating at fast-food restaurants with demographic, behavioural and psychosocial factors and dietary intake in African American adults.

Methods: Self-reported data from a population-based cross-sectional survey of 658 African Americans, aged 20-70 years, in North Carolina. An 11-page questionnaire assessed eating at fast-food restaurants, demographic, behavioural and diet-related psychosocial factors, and dietary intake (fruit, vegetable, total fat and saturated fat intakes, and fat-related dietary behaviours).

Results: The participants were aged $43.9 \pm 11.6$ years (mean \pm standard deviation), $41 \%$ were male, $37 \%$ were college graduates and $75 \%$ were overweight or obese. Seventy-six per cent reported eating at fast-food restaurants during the previous 3 months: $4 \%$ usually, $22 \%$ often and 50\% sometimes. Frequency of eating at fast-food restaurants was positively associated with total fat and saturated fat intakes and fatrelated dietary behaviours $(P<0.0001)$ and inversely associated with vegetable intake $(P<0.05)$. For example, mean daily fat intake was $39.0 \mathrm{~g}$ for usually/often respondents and $28.3 \mathrm{~g}$ for those reporting rare/never eating at fast-food restaurants. Participants who reported usual/often eating at fast-food restaurants were younger, never married, obese, physically inactive and multivitamin non-users (all $P<0.01$ ). Frequency of eating at fast-food restaurants was positively associated with fair/poor self-rated health, weak belief in a diet-cancer relationship, low self-efficacy for healthy eating, weight dissatisfaction, and perceived difficulties of preparing healthy meals and ordering healthy foods in restaurants (all $P<0.05$ ). Frequency of eating at fast-food restaurants did not differ significantly by sex, education, smoking, ability to purchase healthy foods or knowledge of the Food Guide Pyramid.

Conclusions: Eating at fast-food restaurants is associated with higher fat and lower vegetable intakes in African Americans. Interventions to reduce fast-food consumption and obesity in African Americans should consider demographic and behavioural characteristics and address attitudes about diet-disease relationships and convenience barriers to healthy eating.
\end{abstract}

Obesity, always considered an important public health problem, has reached epidemic proportions in the USA in recent years ${ }^{1,2}$. More than two-thirds of US adults are overweight and nearly one in three is obese ${ }^{3,4}$. National surveys indicate that American adults have experienced a $50 \%$ rise in the prevalence of overweight and obesity, increasing from $24.4 \%$ during $1976-1980$ to $35.2 \%$ during $1988-1994^{2}$.

The prevalence of obesity is higher among African Americans than in the general US population. For example, according to a 2001 report of the Surgeon
General, 69\% of African American women and 58\% of African American men are overweight or obese ${ }^{4}$. African Americans also tend to have high rates of weight-related medical conditions, such as diabetes, cardiovascular disease and some cancers ${ }^{3,5,6}$. Moreover, African Americans lag behind other Americans in modifying their diets and activity levels in line with national recommendations ${ }^{3,7}$. Thus, given their high burden of obesity and related negative health outcomes, it is important to identify potentially modifiable contributors to obesity in this population. 
Obesity is a multi-faceted problem that is related to a number of societal, cultural and environmental attributes. Therefore, in identifying factors that may curb the rising trends in obesity, it is important to focus on behavioural components that can be intervened upon. Dietary behaviour is widely considered one of the most important modifiable contributors to the obesity epidemic, and several aspects of diet may be causally related to obesity. Among the potential contributing dietary behaviours, consumption of fast foods is gaining increasing attention $^{8-13}$.

The proportion of Americans who eat away from home has risen dramatically over the past few decades; in 1999, $47.5 \%$ of the US food dollar was spent on food prepared away from home $\mathrm{e}^{14,15}$. Much of the food eaten away from home is consumed at fast-food establishments; for example, in 1997, fast food comprised 34\% of total sales of food away from home, compared with only $4 \%$ in $1953^{16}$. Eating at fast-food restaurants (defined as food purchased in self-service or carry-out eating places without wait service) can contribute to obesity because fast-food meals are generally high in total fat, saturated fat and total energy ${ }^{8-10,17,18}$, thereby potentially contributing to energy imbalance. Furthermore, fast-food restaurant use can adversely affect diet quality; for example, studies have found that fast-food options tend to be low in calcium, folate, vitamins A and C, and dietary fibre ${ }^{19-21}$.

Although the impact of eating at fast-food restaurants on dietary intake and obesity has been examined in various population groups, including women ${ }^{11,14,19}$ and adolescents $^{12}$, to our knowledge these relationships have not been explored in African Americans. Therefore, the objectives of the present study were:

1. to describe the prevalence of eating at fast-food restaurants among African American adults in North Carolina; and

2. to examine cross-sectional associations of eating at fast-food restaurants with dietary intake and demographic, behavioural and diet-related psychosocial factors in this population.

\section{Methods}

\section{Study population and data collection}

The data reported here were collected as part of a study testing different methods and strategies to recruit African Americans into a population-based assessment of cancer behavioural risk factors. Details of the data collection procedures are given elsewhere ${ }^{22}$. Briefly, potential participants were African Americans in North Carolina, aged $18-70$ years $(n=5000)$, who were randomly selected from Department of Motor Vehicle rosters and assigned at random to one of five different recruitment strategies based on variations of approach letters (generic vs. culturally sensitive) and inclusion, exclusion or promise of a small incentive. Specifically, the five recruitment strategies were generic letter only; culturally sensitive letter only; culturally sensitive letter plus promise of an incentive; generic letter plus incentive; and culturally sensitive letter plus incentive. All prospective participants were sent an 11-page questionnaire by mail, but were also given information on how they could complete the survey on the Internet or by telephone instead. The questionnaire assessed various demographic, lifestyle and cancer behavioural risk factors and was pre-tested in a small sample $(n=13)$ before being used in this study. Seven hundred and forty-seven persons completed the questionnaire out of 4276 delivered by the post office (17.5\% response rate): $87.7 \%$ by mail, $11.2 \%$ via the Internet and $1.1 \%$ by telephone. Eighty-nine respondents who did pass age eligibility (missing or ineligible age information) and questionnaire quality control checks (greater than 15\% missing data) were excluded, leaving 658 persons for these analyses ${ }^{22}$. The study was approved by the Institutional Review Board of the School of Public Health at the University of North Carolina-Chapel Hill.

\section{Survey instrument}

We used five sets of questions from the 11-page questionnaire in these analyses: demographic characteristics; behavioural and lifestyle factors; diet-related psychosocial factors; dietary intake; and eating at fastfood restaurants. All data are from self-report.

\section{Fast-food restaurant use}

Frequency of eating at fast-food restaurants during the previous 3 months was assessed using a single item: 'In the past 3 months, did you eat at fast food restaurants, such as McDonalds $^{\circledR}$, Pizza Hut ${ }^{\circledR}$ or fast Chinese restaurants?' ('yes' or 'no'). If 'yes', response options were 'usually', 'often', 'sometimes' and 'rarely/never'. For these analyses, participants who responded 'no' were included in the 'rarely/never' category. In previous studies among women $^{11}$ and adolescents ${ }^{12}$, this single-item measure has successfully distinguished frequent from infrequent eaters at fast-food restaurants with regard to dietary intake and demographic, behavioural and psychosocial factors.

\section{Dietary assessment}

The referent period for dietary intake was 'over the previous 3 months'. Fruit and vegetable consumption was assessed using the 7-item fruit and vegetable screener developed at the National Cancer Institute ${ }^{23,24}$. Fruit intake was the sum of 'fruit juice' and 'fruit, not counting juice', and vegetable intake was calculated as the sum of 'green or lettuce salad', 'potatoes (boiled, baked or mashed)', 'other vegetables', 'beans and peas' and 'vegetables in mixed dishes'. The standard approach for evaluation in the '5-a-Day' programme was used to calculate fruit and vegetable servings per day ${ }^{25}$. 
Dietary fat intake was captured using two instruments: the Block Fat Screener and the Fat-Related Diet Habits Questionnaire. Total fat and saturated fat intakes were estimated using the Block Fat Screener, which is comprised of 13 items designed to capture common sources of fat in the American diet ${ }^{26,27}$. To obtain mean daily intakes, we followed the Block algorithm and multiplied the number of times each item was consumed by the reported age- and sex-specific portion size and summed across the daily intakes for all 13 items. Because the Block Fat Screener assesses intakes of only 13 food items, it does not measure total fat consumption, but rather provides an estimate of fat intake suitable for ranking purposes. The Fat-Related Diet Habits Questionnaire is a 12-item instrument that assesses the following modification techniques: avoiding fat as a flavouring, substituting specially manufactured low-fat foods, modifying meats to be lower in fat, replacing high-fat foods with fruits and vegetables, and avoiding fried foods. Details on the development and validation of this instrument have been published $^{28,29}$. Responses were on a 4-point scale ('usually', 'often', 'sometimes' or 'rarely/never') and coded 1 to 4 so that a high score corresponded to higher fat intake. The summary score was calculated as the mean of the non-missing items.

\section{Demographic, lifestyle and behavioural characteristics}

Various demographic and lifestyle characteristics were assessed, including age (categorised approximately into tertiles), sex, education (less than or equivalent to high school, some college, college graduate, advanced degree), marital status (never married, married/living with partner, divorced/separated/widowed), smoking (never, former, current), current multivitamin use (yes, no) and urban versus rural residence. Body mass index (BMI) was computed as weight (in $\mathrm{kg}$ ) divided by the square of height (in $\mathrm{m}$ ), and further categorised as 'normal' (18.5$24.9 \mathrm{~kg} \mathrm{~m}^{-2}$ ), 'overweight' (25.0-29.9 $\mathrm{kg} \mathrm{m}^{-2}$ ) and 'obese' $\left(\geq 30.0 \mathrm{~kg} \mathrm{~m}^{-2}\right)^{30}$. Physical activity was assessed using a 4 -item questionnaire that ascertained the frequency, duration, pace and intensity of usual recreational physical activities, based on the instrument used in the Prostate Cancer Prevention Trial (PCPT). Details of the tool and its algorithms have been described ${ }^{31}$. Briefly, an activity index was calculated as the multiple of the frequency, duration and pace indices, following the coding scheme described by Ainsworth et al. ${ }^{32}$ and categorised approximately into tertiles of low, moderate and high. Physical activity intensity level was determined based on how often a participant stated $\mathrm{s} /$ he engaged in physical activity long enough to work up a sweat or get out of breath. Based on activity index and intensity level, participants were categorised as having 'sedentary', 'light', 'moderate' or 'very active' activity levels. In the PCPT, physical activity was statistically significantly inversely associated with BMI after control for covariates ${ }^{31}$.

\section{Diet-related psychosocial factors}

Psychosocial factors were adapted from previous research using the PRECEDE/PROCEED planning model ${ }^{33-36}$ and from a dietary intervention trial among African Americans in North Carolina ${ }^{37}$. Participants reported perceptions of their overall health status ('excellent', 'very good', 'good', 'fair' or 'poor') and whether they had ever heard about the US Department of Agriculture's Food Guide Pyramid ('yes', 'no' or 'don't know'). Respondents also indicated whether they believe in a relationship between diet and cancer ('yes' or 'no'), and if 'yes', whether the relationship is strong, moderate or weak. Weight satisfaction was measured using two items: currently doing anything to lose weight ('yes' or 'no') and degree of satisfaction with weight ('very satisfied', 'somewhat satisfied', 'not satisfied' or 'very dissatisfied'). Healthy eating self-efficacy was assessed by two items about self-confidence to eat less fat and more fruits and vegetables using Likert-scaled questions ('very confident', 'somewhat confident' or 'not very confident'). Perceived barriers to healthy eating were evaluated using four items: can afford to purchase healthy foods and meals, takes time and trouble to prepare healthy meals, easy to order healthy foods in restaurants, and need more information on how to prepare healthy foods and meals ('yes', 'sometimes' or 'no/don't know').

\section{Statistical analyses}

Descriptive statistics were computed for frequency of eating at fast-food restaurants, dietary variables, and demographic, behavioural and psychosocial variables; percentages were calculated for categorical variables and means and standard errors computed for continuous variables. Linear regression models were used to examine associations of dietary intake (daily intakes of fruits and vegetables (servings day ${ }^{-1}$ ), total and saturated fat $\left(\mathrm{g} \mathrm{day}{ }^{-1}\right)$ and fat-related dietary behaviours) as the response outcome variables with frequency of eating at fast-food restaurants (categorised as usually/often, sometimes, rarely/never). From these models, least-square means adjusted for age (continuous), sex, education (high school, some college, college graduate, advanced degree), BMI (continuous) and physical activity (sedentary, light, moderate, very active) are given for each category of eating at fast-food restaurants. Two sets of $P$-values are presented: one comparing all frequencies of eating at fast-food restaurants simultaneously and a $P$-value for linear trend. The dietary variables were not transformed because the data were not markedly skewed. Two-way frequencies were computed for various demographic, lifestyle, behavioural and psychosocial factors and frequency categories of eating at fast-food restaurants (Tables 3 and 4 ) and $P$-values generated by chi-square tests indicate statistically different frequency distributions of eating at fast-food restaurants. Statistical tests were two-sided and $P$-values less than 0.05 were considered statistically significant. Data analyses were performed using SAS 8.01 (SAS Institute Inc., Cary, NC, USA). 


\section{Results}

The participants were aged $43.9 \pm 11.6$ years $($ mean \pm standard deviation), $41 \%$ were male, $37 \%$ were college graduates or had an advanced degree, more than half (56\%) were married, 35\% were overweight, 40\% were obese and $82 \%$ were from urban counties. Only $14 \%$ of respondents were current smokers and $41 \%$ reported current multivitamin use.

Table 1 gives the frequencies of eating at fast-food restaurants among study participants during the previous 3 months. There was no effect modification by sex (data not shown), so results are given for all respondents combined. Seventy-six per cent reported eating at a fast-food restaurant during that time period: $4 \%$ usually, $22 \%$ often and $50 \%$ sometimes.

Associations of dietary intake with eating at fast-food restaurants are given in Table 2. After controlling for demographic and behavioural factors, the frequency of eating at fast-food restaurants was positively and linearly associated with total fat and saturated fat intakes and fat-related dietary behaviours $(P<0.0001)$ and inversely correlated with vegetable intake (all $P$ for trend $<0.05$ ). For example, mean daily fat intake was $39.0 \mathrm{~g}$ for respondents who usually/often eat at fast-food restaurants compared with $28.3 \mathrm{~g}$ for those reporting rarely/never, while mean vegetable servings per day were 1.51 and 1.87, respectively, for usually/often and rarely/never

Table 1 Eating at fast-food restaurants among African Americans over the previous 3 months $(n=658)$

\begin{tabular}{lrr}
\hline \multirow{2}{*}{$\begin{array}{l}\text { Eating at fast-food restaurants } \\
\text { over previous 3 months }\end{array}$} & \multicolumn{2}{c}{ Frequency } \\
\cline { 2 - 3 } & $n$ & $\%$ \\
\hline No & 158 & 24 \\
Yes & 500 & 76 \\
Usually & 24 & 4 \\
Often & 147 & 22 \\
Sometimes & 329 & 50 \\
Rarely/never & 158 & 24
\end{tabular}

Note: Percentages may not add up to $100 \%$ due to rounding and missing data. respondents. Eating at fast-food restaurants was not statistically significantly associated with fruit or total fruit and vegetable intakes.

Table 3 gives demographic, lifestyle and behavioural factors associated with eating at fast-food restaurants. Participants who reported usual/often eating at fast-food restaurants were more often younger, never married and physically inactive (all $P<0.0001$ ). For example, there was an almost 10-year age difference between usually/ often and rarely/never respondents and $40 \%$ of those who usually/often eat at fast-food restaurants were sedentary compared with only $14 \%$ of those who rarely/never eat at these establishments. Frequency of eating at fast-food restaurants was also positively associated with obesity (mean BMI 31.3 and $28.6 \mathrm{~kg} \mathrm{~m}^{-2}$, respectively, for usually/ often and rarely/never respondents, $P=0.02$ ) and noncurrent use of multivitamins $(P=0.03)$. Frequency of eating at fast-food restaurants did not differ significantly by sex, education, smoking or urban versus rural residence.

Psychosocial correlates of eating at fast-food restaurants are given in Table 4. Frequent eating at fast-food restaurants was positively associated with fair/poor selfrated health, weak/no belief in a relationship between diet and cancer, low self-efficacy to eat less fat and more fruits and vegetables, and perceived difficulties of preparing healthy meals and ordering healthy foods in restaurants (all $P<0.05$ ). Participants who usually/often eat at fastfood restaurants were also more likely to be dissatisfied with their weight and taking steps to lose weight (35\% vs. $20 \%$ for rarely/never respondents, $P<0.0001)$. Frequency of eating at fast-food restaurants was not associated with financial ability to purchase healthy foods, need for information on how to prepare healthy foods and meals, or knowledge of the Food Guide Pyramid.

\section{Discussion}

Many studies have found that eating outside the home has increased markedly over the past 20-30 years. The current environment in the USA encourages over-consumption of

Table 2 Associations of dietary intake with eating at fast-food restaurants over the previous 3 months $(n=658)$

\begin{tabular}{|c|c|c|c|c|c|c|c|}
\hline \multirow[b]{2}{*}{ Dietary intake* } & \multirow[b]{2}{*}{$n$} & \multicolumn{6}{|c|}{ Eating at fast-food restaurants over previous 3 months (least-square mean†) } \\
\hline & & Mean (SE) & Usually/often & Sometimes & Rarely/never & $\begin{array}{l}P \text { for linear } \\
\text { trend }\end{array}$ & $P$-value $\ddagger$ \\
\hline Fruits (servings day ${ }^{-1}$ ) & 658 & $0.88(0.03)$ & 0.83 & 0.92 & 0.88 & 0.60 & 0.54 \\
\hline Vegetables (servings day ${ }^{-1}$ ) & 658 & $1.64(0.05)$ & $1.51^{\mathrm{a}}$ & $1.67^{\mathrm{a}, \mathrm{b}}$ & $1.87^{\mathrm{b}}$ & 0.02 & 0.07 \\
\hline Fruits and vegetables (servings day ${ }^{-1}$ ) & 658 & $2.52(0.07)$ & 2.34 & 2.59 & 2.75 & 0.06 & 0.15 \\
\hline Fat-related diet habits scale score & 658 & $2.86(0.02)$ & $3.00^{\mathrm{a}}$ & $2.83^{\mathrm{b}}$ & $2.68^{\mathrm{C}}$ & $<0.0001$ & $<0.0001$ \\
\hline Total fat intake $\left(\mathrm{g} \mathrm{day}^{-1}\right)$ & 658 & $31.4(0.8)$ & $39.0^{\mathrm{a}}$ & $30.0^{\mathrm{b}}$ & $28.3^{\mathrm{b}}$ & $<0.0001$ & $<0.0001$ \\
\hline Total saturated fat intake $\left(\mathrm{g} \mathrm{day}^{-1}\right)$ & 658 & $11.9(0.3)$ & $14.6^{\mathrm{a}}$ & $11.3^{\mathrm{b}}$ & $10.9^{\mathrm{b}}$ & $<0.0001$ & $<0.0001$ \\
\hline
\end{tabular}

* Fruit and vegetable intakes are from the National Cancer Institute 7-item questionnaire and fat and saturated fat intakes (g) are from the Block 13-item Fat Screener. For the fat-related diet habits scale score, a high number equals higher fat intake.

† Least-square means are adjusted for age, sex, education, body mass index and physical activity.

$\ddagger P$-value comparing all levels of eating at fast-food restaurants simultaneously.

${ }^{a-c}$ Means with different superscripts are statistically significantly different from each other $(P<0.05)$. 
Table 3 Associations of demographic, lifestyle and behavioural characteristics with eating at fast-food restaurants over the previous 3 months $(n=658)$

\begin{tabular}{|c|c|c|c|c|c|}
\hline \multirow{2}{*}{$\begin{array}{l}\text { Demographic/lifestyle/behavioural } \\
\text { characteristic }\end{array}$} & \multicolumn{4}{|c|}{ Eating at fast-food restaurant over previous 3 months ( $n$ (row \%)) } & \multirow[b]{2}{*}{$P$-value } \\
\hline & $n(\%)$ & Usually/often & Sometimes & Rarely/never & \\
\hline \multicolumn{6}{|l|}{ Age (years) } \\
\hline $20-39$ & $233(35)$ & $87(37)$ & $119(51)$ & $27(12)$ & \multirow[t]{3}{*}{$<0.0001$} \\
\hline $40-49$ & $207(31)$ & $53(26)$ & $102(49)$ & $52(25)$ & \\
\hline $50-70$ & 218 (33) & $31(14)$ & $108(50)$ & $79(36)$ & \\
\hline Mean $\pm \mathrm{SE}^{\star}$ & $43.9 \pm 0.5$ & $39.2(0.9)$ & $44.0(0.6)$ & $48.7(0.9)$ & $<0.0001$ \\
\hline \multicolumn{6}{|l|}{ Sex } \\
\hline Male & $271(41)$ & $62(23)$ & $143(53)$ & $66(24)$ & \multirow[t]{2}{*}{0.21} \\
\hline Female & $378(58)$ & $109(29)$ & $179(47)$ & $90(24)$ & \\
\hline \multicolumn{6}{|l|}{ Education } \\
\hline Less than or equivalent to high school & $146(22)$ & $44(30)$ & $66(45)$ & $36(25)$ & \multirow[t]{4}{*}{0.70} \\
\hline Some college/technical school & $256(39)$ & $64(25)$ & $129(50)$ & $63(25)$ & \\
\hline College graduate & $168(26)$ & $41(24)$ & $92(55)$ & $35(21)$ & \\
\hline Advanced degree & $74(11)$ & $19(26)$ & $35(47)$ & $20(27)$ & \\
\hline \multicolumn{6}{|l|}{ Marital status } \\
\hline Married/living with partner & $368(56)$ & $82(22)$ & $202(55)$ & $84(23)$ & \multirow[t]{3}{*}{$<0.0001$} \\
\hline Divorced/separated/widowed & 107 (16) & $23(21)$ & $46(43)$ & $38(36)$ & \\
\hline Never married & $177(27)$ & $65(37)$ & $79(45)$ & 33 (19) & \\
\hline \multicolumn{6}{|l|}{ Body mass index $\left(\mathrm{kg} \mathrm{m}^{-2}\right)$} \\
\hline Normal (18.5-24.9) & $147(22)$ & $39(27)$ & $62(42)$ & $46(31)$ & \multirow[t]{3}{*}{0.04} \\
\hline Overweight (25.0-29.9) & $227(35)$ & $53(23)$ & $123(54)$ & $51(22)$ & \\
\hline Obese $(\geq 30)$ & $266(40)$ & 77 (29) & $138(52)$ & 51 (19) & \\
\hline Mean $\pm \mathrm{SE}^{*}$ & $30.3 \pm 0.3$ & $31.3(0.6)$ & $30.5(0.4)$ & $28.6(0.5)$ & 0.02 \\
\hline \multicolumn{6}{|l|}{ Current multivitamin use } \\
\hline Yes & $271(41)$ & $57(21)$ & $143(53)$ & $71(26)$ & \multirow[t]{2}{*}{0.03} \\
\hline No & $373(57)$ & $113(30)$ & $180(48)$ & $80(21)$ & \\
\hline \multicolumn{6}{|l|}{ Smoking } \\
\hline Never smoker & $425(65)$ & $116(27)$ & $219(52)$ & $90(21)$ & \multirow[t]{3}{*}{0.42} \\
\hline Former smoker & 124 (19) & $30(24)$ & $58(47)$ & $36(29)$ & \\
\hline Current smoker & $95(14)$ & $23(24)$ & 47 (49) & $25(26)$ & \\
\hline \multicolumn{6}{|l|}{ Physical activity } \\
\hline Sedentary & $188(29)$ & $76(40)$ & $86(46)$ & $26(14)$ & \multirow[t]{4}{*}{0.0001} \\
\hline Light & $139(21)$ & $32(23)$ & $78(56)$ & $29(21)$ & \\
\hline Moderate & $249(38)$ & 48 (19) & $12(50)$ & $77(31)$ & \\
\hline Very active & $59(9)$ & $10(17)$ & $30(51)$ & $19(32)$ & \\
\hline \multicolumn{6}{|l|}{ Urban versus rural residence } \\
\hline Urban & $539(82)$ & $133(25)$ & $277(51)$ & $129(24)$ & \multirow[t]{2}{*}{0.22} \\
\hline Rural & $102(16)$ & $31(30)$ & $43(42)$ & $28(27)$ & \\
\hline
\end{tabular}

Note: Percentages may not add up to $100 \%$ due to rounding and missing data.

* Least-square means and standard errors (SE) are adjusted for age, sex, education, body mass index and physical activity.

$\dagger P$-value comparing all levels of eating at fast-food restaurants simultaneously.

energy and discourages energy expenditure. A number of environmental factors encourage over-consumption including the easy availability of fast-food establishments, the wide variety of inexpensive energy-dense foods and the large portion sizes of these foods ${ }^{38,39}$. Thus, the results of this study indicating that a high proportion of African Americans eat at fast-food restaurants and the associated poorer nutrient profiles are not entirely surprising.

We are not aware of similar studies in African Americans to which we can directly compare our findings; however, there are published data regarding fast-food restaurant use in other population groups. In a study of 891 women by French and colleagues, the authors reported that frequent eating at fast-food restaurants was associated with high total energy intake, high percentage of energy from fat, and less frequent consumption of fibre and fruit. Similar to our findings, frequency of fast-food restaurant use was higher among women who were younger, non-white and heavier. Over a 3-year period, increases in frequency of eating at fast-food restaurants were positively associated with body weight, total energy intake, percentage of energy from fat and decreases in physical activity ${ }^{11}$. In another longitudinal study of 1059 men and women, consuming fast-food meals was positively associated with total energy intake and BMI in women, but not in men, over a 1 -year period $^{10}$. Using data from 1120 women aged 19-50 years who were surveyed over a 1-year period as part of the 1985 Continuing Survey of Food Intake by Individuals, Haines and colleagues reported that women who ate frequently at fast-food establishments had the highest intakes of total energy, total fat, saturated fat, cholesterol and sodium, and low nutrient densities for dietary fibre, calcium, vitamin $\mathrm{C}$ and folate ${ }^{19}$. Our results for African Americans living in North Carolina are in agreement with these other studies.

These findings are concerning because eating at fastfood restaurants clearly results in dietary patterns that increase risk for obesity, a problem disproportionately 
Table 4 Associations of diet-related psychosocial factors with eating at fast-food restaurants over the previous 3 months $(n=658)$

\begin{tabular}{|c|c|c|c|c|c|}
\hline \multirow[b]{2}{*}{ Psychosocial factor } & \multicolumn{4}{|c|}{$\begin{array}{l}\text { Eating at fast-food restaurant over previous } 3 \text { months } \\
\qquad(n(\text { row } \%))\end{array}$} & \multirow[b]{2}{*}{$P$-value* } \\
\hline & $n(\%)$ & Usually/Often & Sometimes & Rarely/never & \\
\hline \multicolumn{6}{|l|}{ Self-rated health } \\
\hline Excellent/very good & $281(43)$ & $51(18)$ & $151(54)$ & $79(28)$ & \multirow[t]{3}{*}{0.0006} \\
\hline Good & $260(40)$ & $79(30)$ & $131(50)$ & $150(19)$ & \\
\hline Fair/poor & $106(16)$ & $38(36)$ & $43(41)$ & $25(24)$ & \\
\hline \multicolumn{6}{|c|}{ Belief in a relationship between diet and cancer } \\
\hline Strong & $136(21)$ & $28(21)$ & $66(49)$ & $42(31)$ & \multirow[t]{3}{*}{0.01} \\
\hline Moderate & $198(30)$ & $44(22)$ & $114(58)$ & $40(20)$ & \\
\hline Weak/don’t know & $324(49)$ & $99(31)$ & $149(46)$ & $76(23)$ & \\
\hline \multicolumn{6}{|c|}{ Confident that you can eat more fruits and vegetables } \\
\hline Very confident & $389(60)$ & $90(23)$ & $203(52)$ & $96(25)$ & \multirow[t]{3}{*}{0.05} \\
\hline Somewhat confident & $208(32)$ & $58(28)$ & $98(47)$ & $52(25)$ & \\
\hline Not very confident & $45(7)$ & $19(42)$ & $20(44)$ & $6(13)$ & \\
\hline \multicolumn{6}{|l|}{ Confident that you can eat less fat } \\
\hline Very confident & $285(44)$ & $57(20)$ & $139(49)$ & $89(31)$ & \multirow[t]{3}{*}{$<0.0001$} \\
\hline Somewhat confident & $280(43)$ & $82(20)$ & $145(52)$ & $53(19)$ & \\
\hline Not very confident & 75 (12) & $30(40)$ & 37 (49) & $8(11)$ & \\
\hline \multicolumn{6}{|c|}{ Currently doing anything to lose weight? } \\
\hline Yes & $285(43)$ & $101(35)$ & $127(45)$ & $57(20)$ & \multirow[t]{2}{*}{$<0.0001$} \\
\hline No & $363(55)$ & 69 (19) & $199(55)$ & $95(26)$ & \\
\hline \multicolumn{6}{|l|}{ Weight satisfaction } \\
\hline Very satisfied & $106(16)$ & $21(20)$ & $51(48)$ & $34(32)$ & \multirow[t]{4}{*}{0.01} \\
\hline Somewhat satisfied & $251(38)$ & $62(25)$ & $127(51)$ & $62(25)$ & \\
\hline Not satisfied & $203(31)$ & $51(25)$ & $112(55)$ & $40(20)$ & \\
\hline Very dissatisfied/don't know & $90(14)$ & $36(40)$ & $37(41)$ & $17(19)$ & \\
\hline \multicolumn{6}{|c|}{ Can afford to purchase healthy foods } \\
\hline Yes & $463(70)$ & $122(26)$ & $229(49)$ & $112(24)$ & \multirow[t]{3}{*}{0.56} \\
\hline Sometimes & $127(19)$ & $29(23)$ & $67(53)$ & $31(24)$ & \\
\hline No/don’t know & $55(8)$ & $18(33)$ & $28(51)$ & 9 (16) & \\
\hline \multicolumn{6}{|c|}{ Takes time/trouble to prepare to prepare healthy meals } \\
\hline Yes & $162(25)$ & $58(36)$ & $73(45)$ & $31(19)$ & \multirow[t]{3}{*}{0.0005} \\
\hline Sometimes & $146(22)$ & $38(26)$ & $85(58)$ & $23(16)$ & \\
\hline No/don’t know & $338(51)$ & $75(22)$ & $165(49)$ & $98(29)$ & \\
\hline \multicolumn{6}{|c|}{ Easy to order healthy foods in restaurants } \\
\hline Yes & $246(37)$ & $56(23)$ & $121(49)$ & $69(28)$ & \multirow[t]{3}{*}{0.03} \\
\hline Sometimes & $205(31)$ & $49(24)$ & $110(54)$ & $46(22)$ & \\
\hline No/don’t know & $196(30)$ & $66(34)$ & $94(48)$ & $36(18)$ & \\
\hline \multicolumn{6}{|c|}{ Need more information on how to prepare healthy foods and meals } \\
\hline Yes & $379(58)$ & $99(26)$ & $198(52)$ & $82(22)$ & \multirow[t]{3}{*}{0.64} \\
\hline Sometimes & $75(11)$ & $21(28)$ & $36(48)$ & $18(24)$ & \\
\hline No/don’t know & $196(30)$ & $51(26)$ & $92(47)$ & $53(27)$ & \\
\hline Heard of the Food Guide Pyran & & & & & \\
\hline Yes & $533(82)$ & $147(28)$ & 259 (49) & $127(23)$ & 0.28 \\
\hline No & $94(14)$ & $20(21)$ & $51(54)$ & $23(24)$ & \\
\hline Not sure/don't know & $25(4)$ & $4(16)$ & $17(68)$ & $4(16)$ & \\
\hline
\end{tabular}

Note: Percentages may not add up to $100 \%$ due to rounding and missing data.

${ }^{*} P$-value comparing all levels of eating at fast-food restaurants simultaneously.

affecting minority populations, particularly African Americans. As noted above, positive associations of frequency of restaurant food/fast-food consumption with total energy intake, percentage energy from fat, BMI and body fatness have been reported ${ }^{8,10,11}$. Poor eating habits are also major contributors to heart disease, cancer, osteoporosis and other serious and costly diseases ${ }^{40}$. Therefore, dietary interventions targeting eating at fastfood restaurants may be of considerable benefit with regard to obesity and chronic disease prevention in this population.

The psychosocial factors associated with frequency of fast-food consumption among our participants are consistent with previous studies reporting that individuals with a weak belief in diet and chronic disease relationships, low self-efficacy for healthy dietary practices and perceived barriers to healthy eating have poorer dietary profiles ${ }^{41-44}$. We also found that a number of unhealthy behaviours, in particular physical inactivity, non-multivitamin use and poor perceived overall health status ${ }^{45}$, were linked to more frequent eating at fast-food restaurants. This clustering of characteristics, as well as the lack of an association with financial barriers, knowledge of the Food Guide Pyramid and need for information on how to prepare healthy meals, suggests that interventions to improve dietary habits in this population should be geared more towards facilitating healthy attitudinal and behavioural changes. This suggestion has also been proposed 
by other investigators conducting interventions to improve fruit and vegetable intakes in African Americans ${ }^{37}$.

It is worth noting that respondents who were concerned about their weight, i.e. those currently taking steps to lose weight and those dissatisfied/very dissatisfied with weight, reported eating at fast-food restaurants more frequently. Although this study is cross-sectional, we did find a higher mean BMI in this sub-population than in those who reported rarely or never eating at fast-food restaurants. Thus, our results suggest that avoiding fast-food establishments may not be part of their weight-control strategies. Clearly, this is a behaviour that dietary intervention and education programmes may need to target.

Our study has a number of strengths. To our knowledge, this is the first study to examine eating at fast-food restaurants and its associations with dietary intake as well as various demographic, lifestyle, behavioural and psychosocial factors in African Americans. We used a comprehensive survey instrument adapted from questionnaires that have been successfully used in other studies $^{11,12,31,34,36,37,42,43}$. The sample was also population-based (as opposed to a convenience sample) and respondents were distributed across various demographic strata, which increases the generalisability of our results.

The study also has some limitations worth mentioning. First, the survey had a relatively low overall response rate, which may limit the generalisability of our findings. We are also unable to compare responders to non-responders with regard to demographic and other participant characteristics, which would have informed on reasons for non-participation and the degree to which respondents were representative of the larger sample. Second, we relied on a single-item measure of eating at fast-food restaurants, which may not be sufficiently precise. Third, all data are from self-report, which is subject to both random and systematic bias ${ }^{46}$. In particular, underreporting of dietary intake and body weight among overweight persons and social desirability bias are of concern ${ }^{47}$. Fourth, the use of brief dietary instruments may result in underestimation of intake and/or misclassification; however, these instruments have been validated in samples that include sizeable numbers of African Americans ${ }^{24,27}$ and the Fat-Related Diet Habits Questionnaire has a good correlation with total fat intake ${ }^{29}$. Finally, because of the cross-sectional design, no inferences can be made regarding the temporal sequence of the associations observed here.

In summary, we found that frequency eating at fast-food restaurants was significantly associated with higher fat intake (total fat, saturated fat, and dietary fat-related behaviours) and lower vegetable consumption in a sample of African Americans in North Carolina. Respondents more likely to frequent fast-food restaurants were younger, obese, sedentary, unmarried, dissatisfied with their weight, less likely to believe in relationships between diet and disease and perceive various impediments to healthy eating. Based on these findings, interventions to reduce consumption of fast foods should address attitudes about diet-disease relationships and convenience barriers to healthy eating. More broadly, educational efforts to improve dietary intake and reduce obesity must consider both demographic and behavioural characteristics and address away-from-home eating, particularly at fast-food establishments. This would allow development of behavioural change strategies that consider food choices dictated by the eating environment, as well as personal knowledge and attitude factors related to adoption of healthy food choices.

\section{References}

1 Flegal KM, Carroll MD, Ogden CL, Johnson CL. Prevalence and trends in obesity among US adults, 1999-2000. Journal of the American Medical Association 2002; 288: 1723-7.

2 Flegal KM, Carroll MD, Kuczmarski RJ, Johnson CL. Overweight and obesity in the United States: prevalence and trends, 1960-1994. International Journal of Obesity and Related Metabolic Disorders 1998; 22: 39-47.

3 US Department of Health and Human Services. Healthy People 2010. Washington, DC: US Public Health Service, 2000.

4 Surgeon General. The Surgeon General's Call to Action to Prevent and Decrease Overweight and Obesity. Washington, DC: US Government Printing Office, 2001.

5 Ghafoor A, Jemal A, Cokkinides V, Cardinez C, Murray T, Samuels A, et al. Cancer statistics for African Americans. CA Cancer Journal for Clinicians 2002; 52(6): 326-41.

6 Clayton LA, Byrd WM. The African-American cancer crisis, Part I: the problem. Journal of Health Care for the Poor and Underserved 1993; 4(2): 83-101.

7 James DC. Gender differences in body mass index and weight loss strategies among African Americans. Journal of the American Dietetics Association 2003; 103(10): 1360-2.

8 McCrory MA, Fuss PJ, Hays NP, Vinken AG, Greenberg AS, Roberts SB. Overeating in America: association between restaurant food consumption and body fatness in healthy adult men and women ages 19 to 80. Obesity Research 1999; 7: $564-71$.

9 Ma Y, Bertone ER, Stanek EJ III, Reed GW, Hebert JR, Cohen NL, et al. Association between eating patterns and obesity in a free-living US adult population. American Journal of Epidemiology 2003; 158: 85-92.

10 Jeffery RW, French SA. Epidemic obesity in the United States: are fast foods and television viewing contributing? American Journal of Public Health 1998; 88(2): 277-80.

11 French SA, Harnack L, Jeffery RW. Fast food restaurant use among women in the Pound of Prevention study: dietary, behavioral and demographic correlates. International Journal of Obesity and Related Metabolic Disorders 2000; 24(10): 1353-9.

12 French SA, Story M, Neumark-Sztainer D, Fulkerson JA, Hannan P. Fast food restaurant use among adolescents: associations with nutrient intake, food choices and behavioral and psychosocial variables. International Journal of Obesity and Related Metabolic Disorders 2001; 25(12): $1823-33$.

13 Harnack L, French S. Fattening up on fast food. Journal of the American Dietetic Association 2003; 103(10): 1296-7.

14 Guthrie JF, Lin BH, Frazao E. Role of food prepared away from home in the American diet, 1977-78 versus 1994-96: changes and consequences. Journal of Nutrition Education and Behavior 2002; 34(3): 140-50. 
15 Clauson A. Spotlight on national food spending. Food Review 2000; (September): 15-7.

16 US Department of Agriculture (USDA). USDA Continuing Survey of Food Intakes by Individuals, 1994-1996. Washington, DC: USDA Economic Research Service, 1997.

17 Lin B, Frazao E, Guthrie J. Away From Home Foods Increasingly Important to Quality of American Diet Agriculture Information Bulletin No. 749. Washington, DC Economic Research Service, US Department of Agriculture, 1999; $12 \mathrm{pp}$

18 Clemens LHE, Slawson DK, Klesges RC. The effect of eating out on quality of diet in premenopausal women. Journal of the American Dietetic Association 1999; 99(4): 442-4.

19 Haines PS, Hungerford DW, Popkin BM, Guilkey DK. Eating patterns and energy and nutrient intakes of US women. Journal of the American Dietetic Association 1992; 92(6): 698-704, 707.

20 Guenther PM, Perloff BP. Effects of Procedural Differences between 1977 and 1987 in the Nationwide Food Consumption Survey on Estimates of Food and Nutrient Intakes. Results from the USDA 1988 Bridging Study. NFCS Report No. 87-M-1. Hyattsville, MD: US Department of Agriculture, 1990

21 Shannon BM, Parks SC. Fast foods: a perspective on their nutritional impact. Journal of the American Dietetic Association 1980; 76(3): 242-7.

22 Satia JA, Galanko JA, Rimer BK. Methods and strategies to recruit African Americans into cancer prevention surveillance studies. Cancer Epidemiology, Biomarkers \& Prevention 2004; in press.

23 Thompson FE, Kipnis V, Subar AF, Krebs-Smith SM, Kahle LL, Midthune D, et al. Evaluation of 2 brief instruments and a food-frequency questionnaire to estimate daily number of servings of fruit and vegetables. American Journal of Clinical Nutrition 2000; 71(6): 1503-10.

24 Warneke CL, Davis M, De Moor C, Baranowski T. A 7-item versus 31-item food frequency questionnaire for measuring fruit, juice, and vegetable intake among a predominantly African-American population. Journal of the American Dietetic Association 2001; 101(7): 774-9.

25 Havas S, Heimendinger J, Damron D, Nicklas TA, Cowan A, Beresford SA, et al. 5 A Day for better health - nine community research projects to increase fruit and vegetable consumption. Public Health Reports 1995; 110(1): 68-79.

26 Block G, Clifford C, Naughton M, Henderson M, McAdams M. A brief dietary screen for high fat intake. Journal of Nutrition Education 1989; 21: 199-207.

27 Block G, Gillespie C, Rosenbaum EH, Jenson C. A rapid food screener to assess fat and fruit and vegetable intake. American Journal of Preventive Medicine 2000; 18(4): $284-8$.

28 Kristal AR, Shattuck AL, Henry HJ. Patterns of dietary behavior associated with selecting diets low in fat: reliability and validity of a behavioral approach to dietary assessment Journal of the American Dietetic Association 1990; 90(2): 214-20.

29 Shannon J, Kristal AR, Curry SJ, Beresford SA. Application of a behavioral approach to measuring dietary change: the fatand fiber-related diet behavior questionnaire. Cancer Epidemiology, Biomarkers \& Prevention 1997; 6(5): 355-61.

30 Clinical guidelines on the identification, evaluation, and treatment of overweight and obesity in adults: executive summary. Expert Panel on the Identification, Evaluation, and Treatment of Overweight in Adults. American Journal of Clinical Nutrition 1998; 68(4): 899-917.

31 Satia-Abouta J, Patterson RE, Schiller RN, Kristal AR. Energy from fat is associated with obesity in US men: results from the Prostate Cancer Prevention Trial. Preventive Medicine 2002; 34(5): 493-501.

32 Ainsworth BE, Haskell WL, Whitt MC, Irwin ML, Swartz AM, Strath SJ, et al. Compendium of physical activities: an update of activity codes and MET intensities. Medicine and Science in Sports and Exercise 2000; 32(Suppl. 9): S498-504.

33 Glanz K, Kristal AR, Sorensen G, Palombo R, Heimendinger J, Probart C. Development and validation of measures of psychosocial factors influencing fat- and fiber-related dietary behavior. Preventive Medicine 1993; 22(3): 373-87.

34 Kristal AR, Patterson RE, Glanz K, Heimendinger J, Hebert JR, Feng $\mathrm{Z}$, et al. Psychosocial correlates of healthful diets: baseline results from the Working Well Study. Preventive Medicine 1995; 24(3): 221-8.

35 Gielen AC, McDonald EM. The PRECEDE-PROCEED planning model. In: Glanz K, Lewis FM, Rimer BK, eds. Health Behavior and Health Education: Theory, Research, and Practice, 3rd ed. San Francisco, CA: Jossey-Bass Inc., 2002; 409-36

36 Satia-Abouta J, Patterson RE, Kristal AR, Teh C, Tu SP. Psychosocial predictors of diet and acculturation in Chinese American and Chinese Canadian women. Ethnicity \& Health 2002; 7(1): 21-39.

37 Campbell MK, Symons M, Demark-Wahnefried W, Polhamus B, Bernhardt JM, McClelland JW, et al. Stages of change and psychosocial correlates of fruit and vegetable consumption among rural African-American church members. American Journal of Health Promotion 1998; 12(3): 185-91.

38 Nielsen SJ, Siega-Riz AM, Popkin BM. Trends in food locations and sources among adolescents and young adults. Preventive Medicine 2002; 35(2): 107-13.

39 Nielsen SJ, Popkin BM. Patterns and trends in food portion sizes, 1977-1998. Journal of the American Medical Association 2003; 289(4): 450-3.

40 Weisburger JH. Lifestyle, health and disease prevention: the underlying mechanisms. European Journal of Cancer Prevention 2002; 11(Suppl. 2): S1-7.

41 Vallis M, Ruggiero L, Greene G, Jones H, Zinman B, Rossi S, et al. Stages of change for healthy eating in diabetes: relation to demographic, eating-related, health care utilization, and psychosocial factors. Diabetes Care 2003; 26(5): 1468-74.

42 Patterson RE, Kristal AR, White E. Do beliefs, knowledge, and perceived norms about diet and cancer predict dietary change? American Journal of Public Health 1996; 86(10): $1394-400$

43 Kristal AR, Hedderson MM, Patterson RE, Neuhouser M, Neuhouser ML. Predictors of self-initiated, healthful dietary change. Journal of the American Dietetic Association 2001; 101(7): $762-6$.

44 Harnack L, Block G, Subar A, Lane S, Brand R. Association of cancer prevention-related nutrition knowledge, beliefs, and attitudes to cancer prevention dietary behavior. Journal of the American Dietetic Association 1997; 97(9): 957-65.

45 Patterson RE, Neuhouser ML, White E, Hunt JR, Kristal AR. Cancer-related behavior of vitamin supplement users. Cancer Epidemiology, Biomarkers \& Prevention 1998; 7(1): 79-81.

46 Armstrong BK, White E, Saracci R. Principles of Exposure Measurement in Epidemiology. New York: Oxford University Press, 1994.

47 Horner NK, Patterson RE, Neuhouser ML, Lampe JW, Beresford SA, Prentice RL. Participant characteristics associated with errors in self-reported energy intake from the Women's Health Initiative food-frequency questionnaire. American Journal of Clinical Nutrition 2002; 76(4): 766-73. 